\title{
Metabolites produced by Gnomoniopsis castanea associated with necrosis of chestnut galls
}

\author{
Francesco Vinale ${ }^{1 *}$, Michelina Ruocco ${ }^{1}$, Gelsomina Manganiello², Emilio Guerrieri', Umberto Bernardo ${ }^{1}$, \\ Pierluigi Mazzei ${ }^{3}$, Alessandro Piccolo ${ }^{3}$, Filomena Sannino ${ }^{3}$, Simonetta Caira ${ }^{4}$, Sheridan L Woo ${ }^{1,2}$ and Matteo Lorito ${ }^{1,2}$
}

\begin{abstract}
In this manuscript, we report the isolation and characterization of two secondary metabolites produced by a Gnomoniopsis castanea strain isolated in the Campania region (Italy) from chestnut galls infested with Dryocosmus kuriphilus. The compounds, purified from the fungal culture filtrate by using preparative HPLC-DAD, showed the same spectroscopic data of abscisic acid and 1',4'-diol of abscisic acid. Phytotoxic activity of the isolated metabolites on chestnut leaves has been also observed.
\end{abstract}

Keywords: Dryocosmus kuriphilus; Gnomoniopsis castanea; Abscisic acid; 1',4'-Diol of abscisic acid; Fungal secondary metabolites

\section{Findings}

Many cultivated varieties of chestnut (Castanea spp.) are subjected to severe infestations caused by the chestnut gall wasp Dryocosmus kuriphilus Yasumatsu (Hymenoptera: Cynipidae), which can disrupt the fruiting process and reduce a tree's yield by up to $70 \%$. In addition to pest infestation, necrotic symptoms on leaves and galls are often observed due to the development of a gall colonizer identified as the fungus Gnomoniopsis sp. [1]. The new species Gnomoniopsis castanea has been recently described, based on the association with Castanea sativa, the morphology and the phylogenetic analysis of the internal transcribed spacer (ITS) regions of ribosomal DNA and the EF1-a locus. The fungus has been associated with nut rot and caused disease symptoms when artificially inoculated on fruits or flowers [2].

Many fungi exert their effects on plant synthesizing secondary metabolites that alone reproduce some or even all of the symptoms of the disease caused by the producer organism. Moreover, some fungi interfere with the physiology of the plants by producing hormones, such as gibberellin, gibberellic acid, or indole-3-acetic acid [3].

Here, we report the isolation and characterization of the major secondary metabolites produced in liquid culture

\footnotetext{
* Correspondence: f.vinale@ipp.cnr.it

${ }^{1}$ CNR, Istituto per la Protezione Sostenibile delle Piante via Università 133, Portici, NA 80055, Italy

Full list of author information is available at the end of the article
}

by a Gnomoniopsis strain isolated in the Campania region (Italy) from chestnut galls infested with D. kuriphilus. Sequence analysis of the ITS rDNA region indicated 99\% similarity with GenBank sequences of G. castanea confirming the identity of this species characterized as the main causal agent of rot of the ripe nuts, both before and after picking [2].

In order to isolate the major secondary metabolites, ten 7-mm-diameter plugs of G. castanea, obtained from actively growing margins of PDA cultures, were inoculated into 5 - $\mathrm{L}$ conical flasks containing $1 \mathrm{~L}$ of sterile potato dextrose broth (PDB). The stationary cultures were incubated for 21 days at $25^{\circ} \mathrm{C}$. The cultures $(6 \mathrm{~L})$ were filtered under vacuum through a filter paper, acidified to $\mathrm{pH} 4$ with $5 \mathrm{M}$ $\mathrm{HCl}$, and extracted exhaustively with ethyl acetate. The combined organic fraction was dried $\left(\mathrm{Na}_{2} \mathrm{SO}_{4}\right)$ and evaporated in vacuo at $35^{\circ} \mathrm{C}$. The red residue recovered (430 mg) was subjected to flash column chromatography (silica gel) with gradient elution (petrol/ethyl acetate), which resulted in four distinct fractions. Fraction 1 gave a mixture of fatty acids $(40 \mathrm{mg})$, while fractions 3 and 4 (80 mg) were further purified by preparative HPLC-DAD to afford $10 \mathrm{mg}$ of abscisic acid (ABA; Figure 1) and $6 \mathrm{mg}$ of its precursor, 1',4'-trans-diol ABA (diol ABA; Figure 1). The compounds (only released in culture filtrates, while absent in the mycelium extract) were characterized by spectroscopic methods, including UV, LC-MS/MS (Figure 2), and 1D and 2D NMR analyses, and showed the 

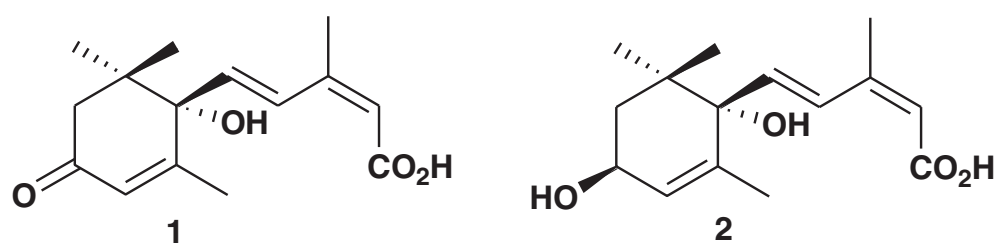

Figure 1 (+)ABA 1 and 1',4-'trans-diol (+)ABA 2.

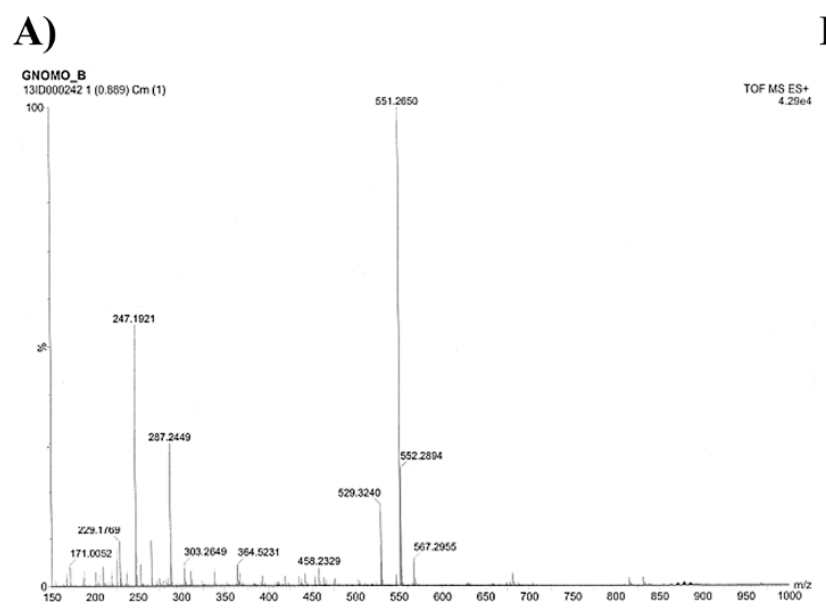

B)

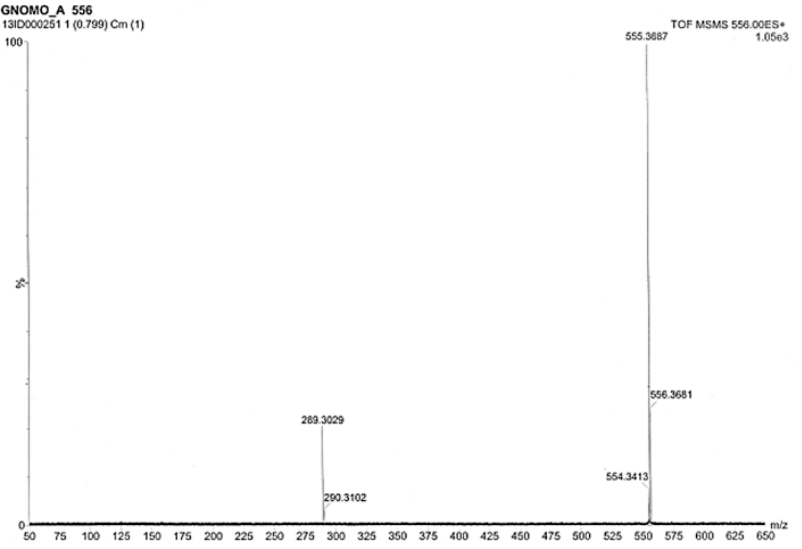

Figure 2 Mass spectra of (+)ABA 1 and 1',4'-trans-diol (+)ABA 2. (A) Mass spectrum of (+)ABA $1-[\mathrm{M}+\mathrm{Na}]^{+}=287.24,\left[\mathrm{MH}-\mathrm{H}_{2} \mathrm{O}\right]^{+}=247.19$, $\left[\mathrm{M}_{2}+\mathrm{H}\right]^{+}=529.32,\left[\mathrm{M}_{2}+\mathrm{Na}\right]^{+}=551.26,\left[\mathrm{M}_{2}+\mathrm{K}\right]^{+}=567.30$. (B) Mass spectrum of 1',4'-trans-diol (+)ABA $2-[\mathrm{M}+\mathrm{Na}]^{+}=289.30,\left[\mathrm{M}_{2}+\mathrm{Na}\right]^{+}=555.37$.

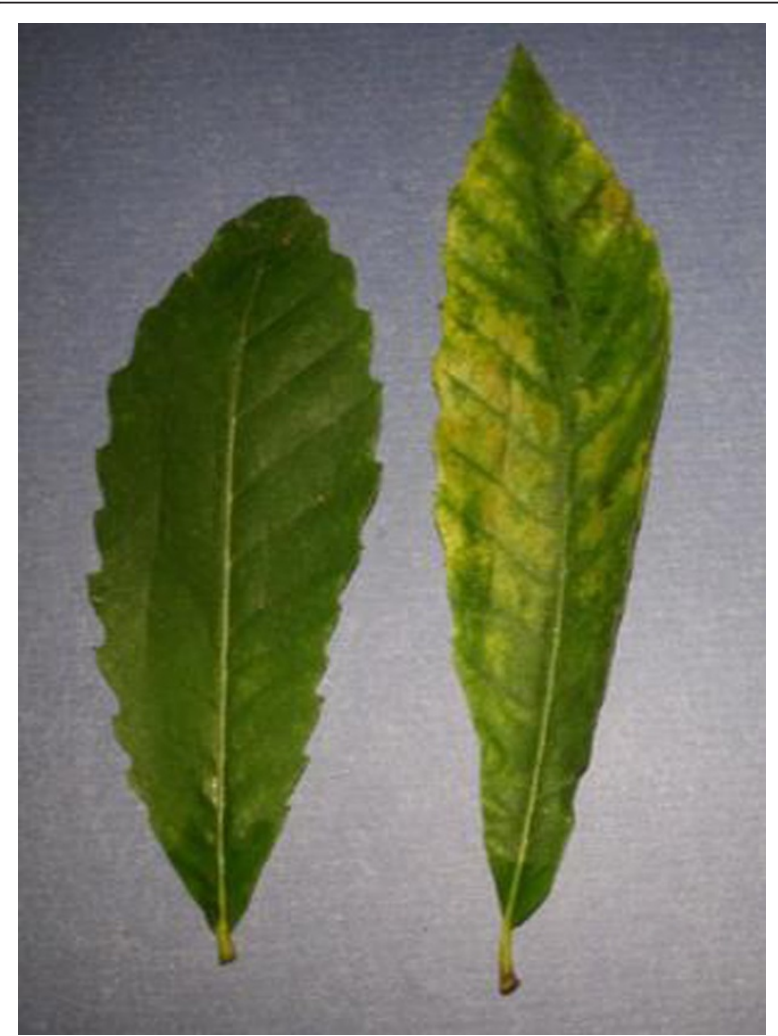

Figure 3 Phytotoxic effect of (+)ABA at concentration of $0.1 \mu \mathrm{g} / \mathrm{ml}$ (right) compared with control (left).

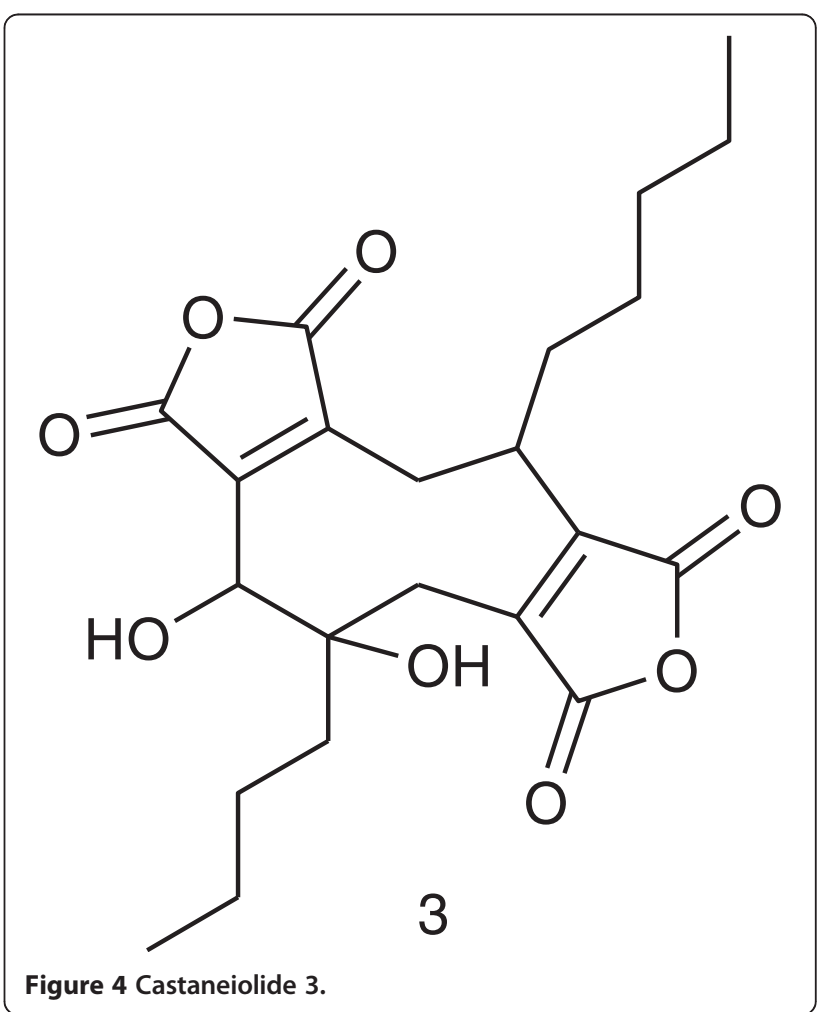


same data of those given in the literature for ABA [4] and its diol derivative [5].

The phytotoxic activity of the isolated metabolites was also tested. A fresh chestnut leaf was inserted into an aqueous solution of $(+) \mathrm{ABA}$ or diol (+)ABA at 100, 10, $1,0.1,0.01$, and $0.001 \mathrm{ppm}$ and compared with controls. The phytotoxic activity was monitored on the leaves by measuring the necrotic and/or chlorotic area formed at room temperature. Phytotoxic activity on chestnut leaves was observed at 1, 10, and $100 \mathrm{ppm}$ (Figure 3) $48 \mathrm{~h}$ after treatment, while no toxic activity was registered at lower concentrations.

Hormones or hormone-like molecules typically have an optimum activity in terms of plant growth regulation between $10^{-5}$ and $10^{-6} \mathrm{M}$ while having a toxic effect at higher concentrations [6].

Some phytopathogenic fungi like Cercospora spp., Botrytis cinerea, Rhizoctonia solani, Fusarium oxysporum, Ceratocystis coerulescens produce $(+) \mathrm{ABA}$ and its biosynthetic analogs [7]. Interestingly, Macrophoma castaneicola, a pathogen causing chestnut black root rot disease, produce two main toxic metabolites on chestnut leaves identified as castaneiolide (Figure 4) and (+)ABA (Figure 1) [8].

ABA has been considered a negative regulator of disease resistance. This effect is due to the interference of ABA with biotic stress signalling that is regulated by salicylic acid, jasmonic acid, and ethylene, and to an additional effect on shared components of stress signalling [9]. The production of ABA by fungi may interfere with the normal physiology of the plant and could explain why phytopathogens secrete this metabolite to plants exogenously.

\section{Competing interests}

The authors declare that they have no competing interests.

\section{Authors' contributions}

All authors have contributed substantially to the work. FV drafted the manuscript; FV, GM, PM, AP, FS, SC: isolation and characterization of metabolites; MR, EG, UB: growth and fungal isolation; SW, ML: biological characterization. They read and approved the final manuscript.

\section{Author details}

${ }^{1}$ CNR, Istituto per la Protezione Sostenibile delle Piante via Università 133 Portici, NA 80055, Italy. ${ }^{2}$ Dipartimento di Agraria, Università degli Studi di Napoli Federico II via Università 100, Portici, NA 80055, Italy. ${ }^{3}$ Centro Interdipartimentale di Spettroscopia di Risonanza Magnetica Nucleare (CERMANU), Università degli Studi di Napoli Federico II via Università 100, Portici, NA 80055, Italy. ${ }^{4}$ CNR, Istituto di Scienze dell'Alimentazione (ISA-CNR) via Roma 64, Avellino, 83100, Italy.

Received: 7 April 2014 Accepted: 12 July 2014

Published online: 15 August 2014

\section{References}

1. Maresi G, Oliveira Longa CM, Turchetti T (2013) Brown rot on nuts of Castanea sativa Mill: an emerging disease and its causal agent. iForest 6:294-301
2. Visentin I, Gentile S, Valentino D, Gonthier P, Tamietti G, Cardinale F (2012) Gnomoniopsis castanea sp. nov. (Gnomoniaceae, Diaporthales) as a causal agent of nut rot in sweet chestnut. J Plant Pathol 94:411-419

3. Möbius N, Hertweck C (2009) Fungal phytotoxins as mediators of virulence. Curr Opin Plant Biol 12:390-398

4. Assante G, Merlini L, Nasini G (1977) (+)-Abscisic acid, a metabolite of the fungus Cercospora rosicola. Cell Mol Life Sci 33:1556-1557

5. Hirai N, Okamoto M, Koshimizu K (1986) The 1',4'-trans-diol of abscisic acid a possible precursor of abscisic acid in Botrytis cinerea. Phytochemistry 25:1865-1868

6. Vinale F, Sivasithamparam K, Ghisalberti EL, Marra R, Woo SL, Lorito M (2008) Trichoderma-plant-pathogen interactions. Soil Biol Biochem 40:1-10

7. Oritani T, Kiyota (2003) Biosynthesis and metabolism of abscisic acid and related compounds. Nat Prod Rep 20:414-425

8. Arai K, Shimizu S, Miyajima H, Yamamoto Y (1989) Castaneiolide, abscisic acid and monorden, phytotoxic compounds isolated from fungi (Macrophoma castaneicola) and (Didymosporium radicicola) cause "black root rot disease" in chestnut trees. Chem Pharm Bull 37:2870-2872

9. Mauch-Mani B, Mauch F (2005) The role of abscisic acid in plant-pathogen interactions. Curr Opin Plant Biol 8:409-414

doi:10.1186/s40538-014-0008-y

Cite this article as: Vinale et al:: Metabolites produced by Gnomoniopsis castanea associated with necrosis of chestnut galls. Chemical and Biological Technologies in Agriculture 2014 1:8.

\section{Submit your manuscript to a SpringerOpen ${ }^{\circ}$ journal and benefit from:}

- Convenient online submission

$\checkmark$ Rigorous peer review

- Immediate publication on acceptance

- Open access: articles freely available online

- High visibility within the field

- Retaining the copyright to your article

Submit your next manuscript at springeropen.com 